\title{
Development of an innovative type of shear connector dedicated to fully embedded steel-concrete composite columns - experimental and numerical investigations
}

\author{
M. Chrzanowski ${ }^{a *}$, C. Odenbreit ${ }^{a}$, R. Obiala ${ }^{b}$, T. Bogdan ${ }^{b}$, M. Braun ${ }^{a}$ and H. Degée ${ }^{c}$ \\ aFSTC, RUES, AMCSFE, University of Luxembourg, Luxembourg \\ ${ }^{b}$ R\&D Global Esch, CIA, ArcelorMittal, Luxembourg \\ 'FET, CERG, Hasselt University, Belgium \\ *corresponding author, e-mail address: maciej.chrzanowski@uni.lu
}

\begin{abstract}
A shear connection in steel-concrete composite columns is established in the normal case with headed shear studs. However, this type of connector has been developed for composite beams and in terms of composite columns, a wide range for an optimisation still can be identified due to the different geometries of steel profiles, concrete and reinforcement.

The presented paper shows investigations on a new type of shear connector with a direct application to composite columns and with a potential for a fully automatic fabrication process. The proposed new type of shear connection is made out of reinforcement bars welded to the external surfaces of the steel profile's flanges.

The experimental campaign consisted of 12 composite push-out tests with a column section geometry. The analysed specimens included centrally embedded HEB120 steel profiles into $340 \times 1000 \times 450 \mathrm{~mm}$ concrete blocks. All the tests have been categorized into 4 groups. One group per connector was defined (including group without mechanical connector). Each group had 3 identical specimens. Surface treatment conditions, reinforcement arrangement, used materials and test layout were the same in all executed tests.

The acquired results showed a good performance of the proposed solutions and allowed to identify the different load-bearing behaviour. After the test execution, the specimens were opened and the failure pattern has been investigated.

The testing campaign was supported by numerical simulations performed with the finite element software code Abaqus ${ }^{\circledR}$. In the developed models, a new approach to simulate the steel-concrete bond was implemented.
\end{abstract}

Keywords: Composite steel-concrete columns, shear connection, steel-concrete bond, mechanical shear connector, shear stresses analysis, load-slip behaviour.

\section{Introduction}

The current practice for shear connection in fully embedded steel-concrete composite columns includes in most cases only headed shear studs welded to the steel profile [1]. The behaviour of this type of connectors in solid slabs was comprehensively investigated for example by Lungershausen [2] or Lam et al. [3]. Rarely, and among others, the shear connection is also applied in the form of welded stiffeners [4] between steel profile's flanges, by the welded perforated plates with reinforcement bars passing through them, perfobond connections [5] or channel sections [6]. Their common feature is, that they have been developed for steel-concrete composite beams (an analogy can be found in the current design codes [6-10]) and their fabrication is cost-inclusive. For big members, e.g. columns in high-rise buildings, this aspect is significant.

Due to the different forces in beam and column members, an area for an optimisation in terms of shear connection is revealed. In the presented paper, the development of a highperforming, feasible and efficient type of a novel mechanical shear connector dedicated to composite columns, with an application to the heavy composite columns with multiple encased 
steel profiles is given. The efficiency criterion defined by the applicability restrictions resulted in easy-applicable solutions with a high potential for the full-automatic fabrication process.

The proposed connectors are fabricated out of reinforcement bars welded to the external surfaces of steel profile's flanges under a special arrangement (see Fig 1.). Three load-bearing mechanisms have been investigated: steel/rebarconcrete bond, friction and mechanical dowel action [11-13].

In the presented work, experimental tests of three different shear connectors' geometries and one series of reference tests without mechanical connectors are described. Results and failure pattern of each of the variants are given and compared to each other. The experimental results were used to calibrate numerical models in FE code Abaqus ${ }^{\circledR}$ [14]. This allows investigating the shear stresses distribution within the concrete matrix and to further develop an analytical model.

\section{Overview}

The experimental campaign included 12 composite column push-out tests (POT). The specimen geometry, reinforcement arrangement, surface treatment and used materials for all of the tests were identical. In all tests, a HEB 120 $\mathrm{L}=550 \mathrm{~mm} \quad \mathrm{~S} 355$ steel profile and a 340x1000x450mm C25/30 concrete block were used. The tests comprised 4 different types of the shear connection, with 3 tests per type (see Table 1 and Fig. 1):

- Pure steel profile, 0v2 type, no mechanical connection between steel and concrete,

- Transversal orientation, Av2 type, reinforcement bars welded perpendicular to the longitudinal axis of the steel profile,

- Angled orientation, Bv2 type, reinforcement bars welded in $45^{\circ}$ orientation to the longitudinal axis of the steel profile (V-shape),

- Longitudinal orientation, Cv2 type, reinforcement bars welded in parallel to the longitudinal axis of the steel profile.

The separation force between the concrete and the steel profile, which is taken in the normal case by the head of the shear stud, is taken in the case of the investigated types of connectors by the surrounding reinforcement cage.
Table 1. Push-out test specimen overview.

\begin{tabular}{|c|c|c|c|c|}
\hline Type & $\begin{array}{l}\text { Sub } \\
\text { No. }\end{array}$ & $\begin{array}{l}\text { Shear } \\
\text { conn. }\end{array}$ & $\begin{array}{c}\text { Material } \\
\text { Geometry } \\
{[\mathrm{mm}]}\end{array}$ & $\begin{array}{l}\text { Surface } \\
\text { treatment }\end{array}$ \\
\hline 0v2 & $\begin{array}{l}-1 \\
-2 \\
-3\end{array}$ & $\begin{array}{l}\text { Bond/ } \\
\text { Friction }\end{array}$ & $\begin{array}{l}\text { Concrete: } \\
\text { C25/30 } \\
340 \times 1000\end{array}$ & Cleaning: \\
\hline Av2 & $\begin{array}{l}-1 \\
-2 \\
-3\end{array}$ & $\begin{array}{l}\text { Rebar } \\
\text { Transv. }\end{array}$ & $\begin{array}{l}\text { Steel: } \\
\text { S355 }\end{array}$ & Coating: \\
\hline Bv2 & $\begin{array}{l}-1 \\
-2 \\
-3\end{array}$ & $\begin{array}{l}\text { Rebar } \\
\text { Angled }\end{array}$ & $\begin{array}{c}\text { HEB } 120 \\
\mathrm{~L}=550 \mathrm{~mm} \\
\text { Embedded }\end{array}$ & $\begin{array}{l}\text { Ant1- } \\
\text { Adhesive } \\
\text { Release } \\
\text { Agent }\end{array}$ \\
\hline Cv2 & $\begin{array}{l}-1 \\
-2 \\
-3\end{array}$ & $\begin{array}{l}\text { Rebar } \\
\text { Long. }\end{array}$ & $\begin{array}{l}\text { length: } \\
\text { 350mm }\end{array}$ & \\
\hline
\end{tabular}

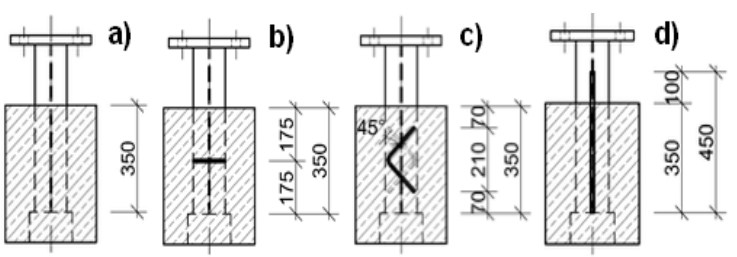

Fig. 1. Types of the shear connectors - a) 0v2, b) Av2, c) Bv2 and d) Cv2.

\section{Experimental test campaign}

The test specimens have been produced at the University of Luxembourg and the tests have been executed in the laboratories of the University of Luxembourg (0v2, Av2 and Cv2 type specimens) and TU Kaiserslautern, Germany (Bv2 type specimens). The test layout in all the tests was identical. The specimens were placed vertically on the rigid platform and the force was imposed vertically to the steel part conducting a relative slip between the steel profile and the concrete encasement.

\subsection{Geometry and material properties}

The geometry of the executed POTs is presented in Fig. 2. At the bottom of each of the specimen, a recession with dimensions of $160 \times 340 \times 100 \mathrm{~mm}$ has been placed centrally to allow a downward slide of the embedded steel profile and to assure an appropriate distribution of the compression stresses within the concrete matrix ( $45^{\circ}$ dispersion angle of the compression strut was designed). For all of the steel profiles, no cleaning process has been applied. A steel surface coating with the usage of the HighPerformance Anti-Adhesive Release Agent 
(demoulding oil) - WETCAST FormFluid HP of the Hebau Company has been implemented in order to minimise the steel-concrete bond phenomenon contribution in the shear force transfer mechanism. An influence of the applied bond-reducing product on the shear stresses at the steel-concrete interface was investigated and described in detail by Chrzanowski et al. [13].

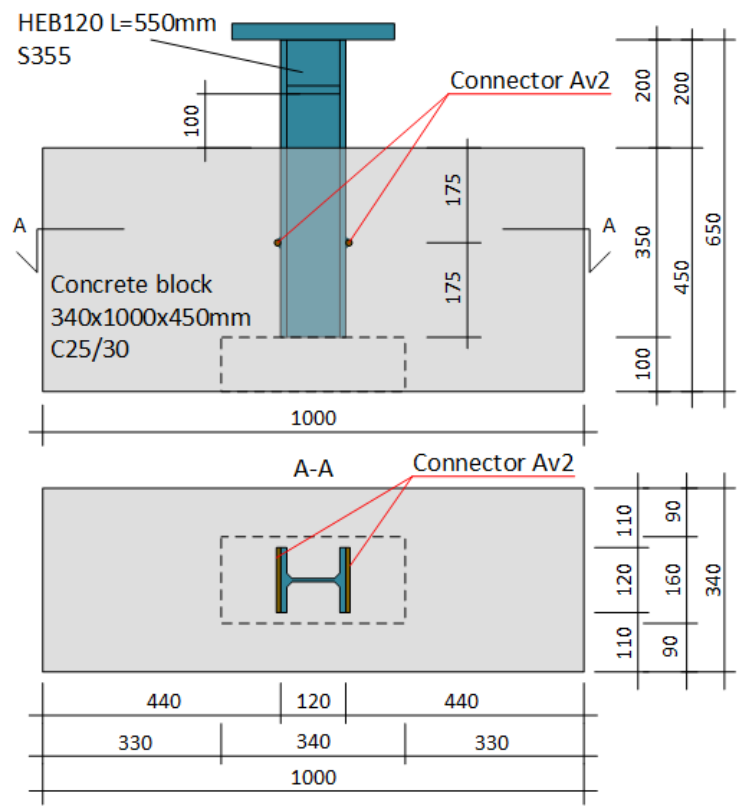

Fig. 2. Specimen geometry with connector Av2.

The reinforcement cage in each of the specimen was identical and it contained three different types of the reinforcement bars: 1) longitudinal bars $(\varnothing 10 / 180(185) \mathrm{L}=380)$, 2) closed stirrups $(\varnothing 12 / 116(117) \mathrm{L}=2615)$ and 3) U-links $(\varnothing 12 / 116(117) \quad L=525)$. The arrangement of the rebar cage is given in Fig. 3.

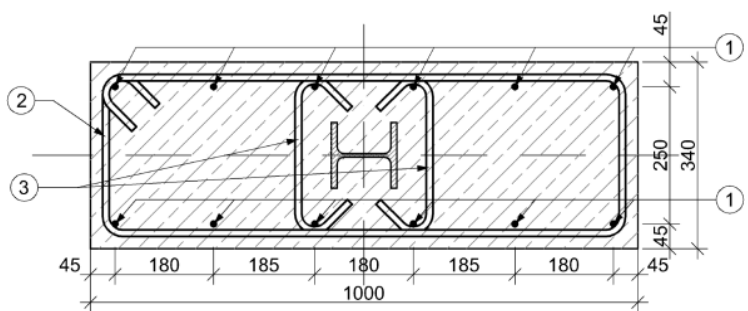

Fig. 3. POT specimen reinforcement cage.

The material properties of structural steel, reinforcement bars and concrete are given in Table 2 and Table 3. The material properties were obtained experimentally. Each specimen with the sub-number "-3" was fabricated with the usage of the same concrete mixture from the same company, but from a different concrete delivery. Due to this fact, the second series of the concrete strength values are given in Table 3 .
Table 2. Steel and reinforcement material properties.

\begin{tabular}{cccc}
\hline Properties & $\begin{array}{c}\text { HEB120 } \\
\text { S355 JR+M }\end{array}$ & RB 500B & Unit \\
\hline $\begin{array}{c}\mathrm{R}_{\mathrm{eH}}, \text { yield } \\
\text { strength }\end{array}$ & 455 & 565 & $\mathrm{MPa}$ \\
$\begin{array}{c}\mathrm{R}_{\mathrm{m}} \text {, tensile } \\
\text { strength }\end{array}$ & 527 & 665 & $\mathrm{MPa}$ \\
$\begin{array}{c}\text { E, elastic } \\
\text { modulus }\end{array}$ & 208000 & 206000 & $\mathrm{MPa}$ \\
A, elongation & 26.5 & 29 & $\%$ \\
\hline
\end{tabular}

Table 3. Concrete material properties.

\begin{tabular}{cccc}
\hline $\begin{array}{c}\text { Grade: C25/30 } \\
\text { Properties }\end{array}$ & $\begin{array}{c}\text { Value } \\
\mathbf{1}^{\text {st }} \text { series }\end{array}$ & $\begin{array}{c}\text { Value } \\
2^{\text {nd }} \text { series }\end{array}$ & Unit \\
\hline $\mathrm{f}_{\mathrm{cm}},(28$ days) & 40.92 & - & $\mathrm{MPa}$ \\
$\mathrm{f}_{\text {cm,cube, }},(28$ days) & 44.93 & 40.59 & $\mathrm{MPa}$ \\
$\mathrm{f}_{\text {cm,cube }},(0 \mathrm{v} 2)$ & 44.93 & 40.59 & $\mathrm{MPa}$ \\
$\mathrm{f}_{\mathrm{cm}, \text { cube }},(\mathrm{Av} 2)$ & 55.55 & 45.92 & $\mathrm{MPa}$ \\
$\mathrm{f}_{\mathrm{cm}, \text { cube }},(\mathrm{Bv} 2)$ & 58.41 & 51.92 & $\mathrm{MPa}$ \\
$\mathrm{f}_{\mathrm{cm}, \text { cube }},(\mathrm{Cv} 2)$ & 50.86 & 45.92 & $\mathrm{MPa}$ \\
\hline
\end{tabular}

$\mathrm{f}_{\mathrm{cm}}-$ compression strength, cylinders $(150 \times 300 \mathrm{~mm})$ $\mathrm{f}_{\mathrm{cm}, \text { cube }}-$ compression strength, cubes $(150 \mathrm{~mm})$

The used shear connectors (see Fig. 4) were made out of regular reinforcement bars RB500B grade. For the specimen types Av2 and Bv2, the diameter of the used rebars was $8 \mathrm{~mm}$. For the specimen type $\mathrm{Cv} 2$, a $12 \mathrm{~mm}$ diameter rebar was used. The connectors were placed symmetrically on both sides of the steel profile. The exemption was Bv2 type specimen where an antisymmetric arrangement was used.

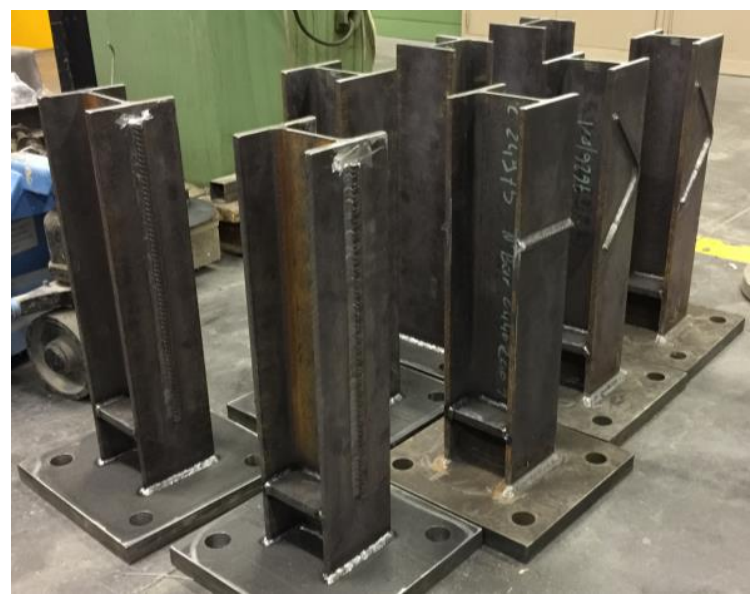

Fig. 4. Novel shear connectors.

\subsection{Test setup and testing procedure}

Two different test setups have been used, see Fig. 5-8. At the University of Luxembourg (UniLux), the specimens were placed on a $10 \mathrm{~mm}$ thick mortar bedding, whereas at the TU Kaiserslautern (TU-K), the specimens were 
placed on the $10 \mathrm{~mm}$ thick elastomer plate and connected to the hydraulic press with a calotte. In comparison to the mortar bedding, the elastomer plate allowed for a bigger local rotation of the concrete block at the specimen's base (Elastic modulus difference). In the result, a bigger normal separation at the steel-concrete interface developed. Therefore, the peak load of the $\mathrm{Bv} 2$ specimens has been reduced.

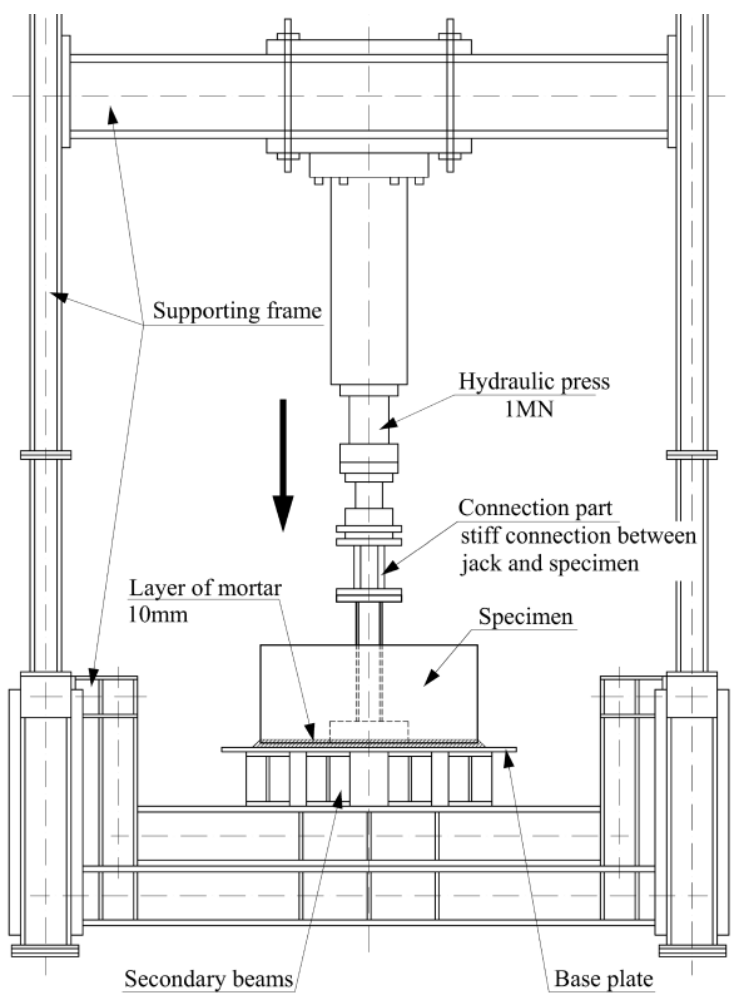

Fig. 5. Test setup at the UniLux.

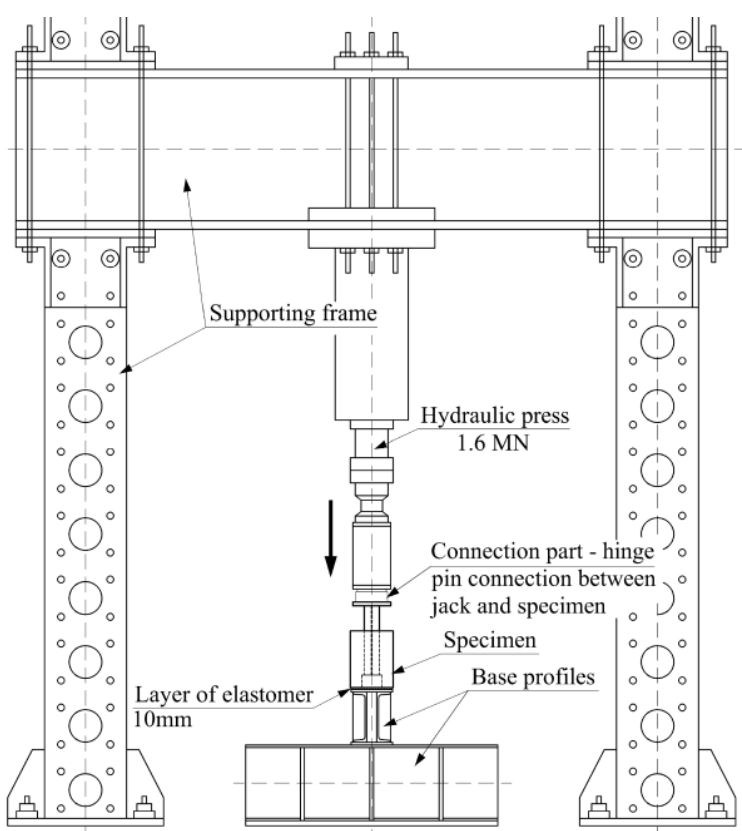

Fig. 6. Test setup at the TU-K.
The testing procedure defined in Eurocode 4 (EN1994-1-1:2004 Annex B [8]) followed. Load increments had a shape of a relative ramp. 25 cycles were performed with an amplitude between $5-40 \%$ of the expected failure load at a frequency of $0.015 \mathrm{~Hz}$. Between each load increment, a pause of approx. 5 min was respected. In the post-failure part of the test, the specimens were continuously loaded with a constant travel rate up to $90 \mathrm{~mm}$ of relative slip.

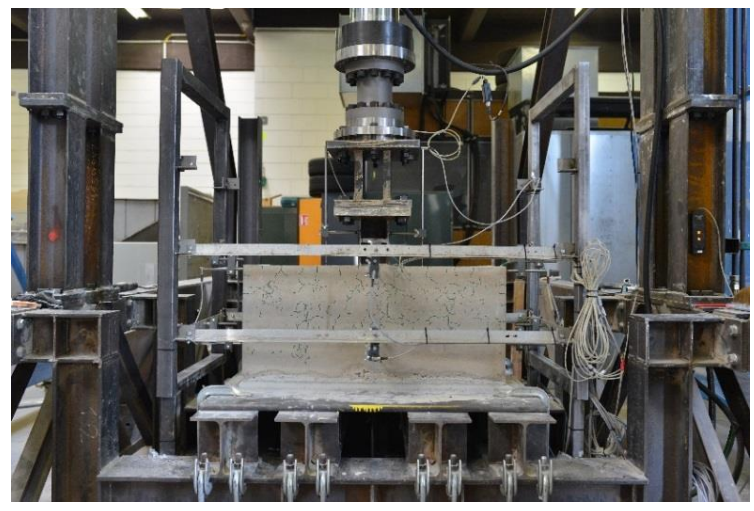

Fig. 7. Test arrangement at the UniLux.

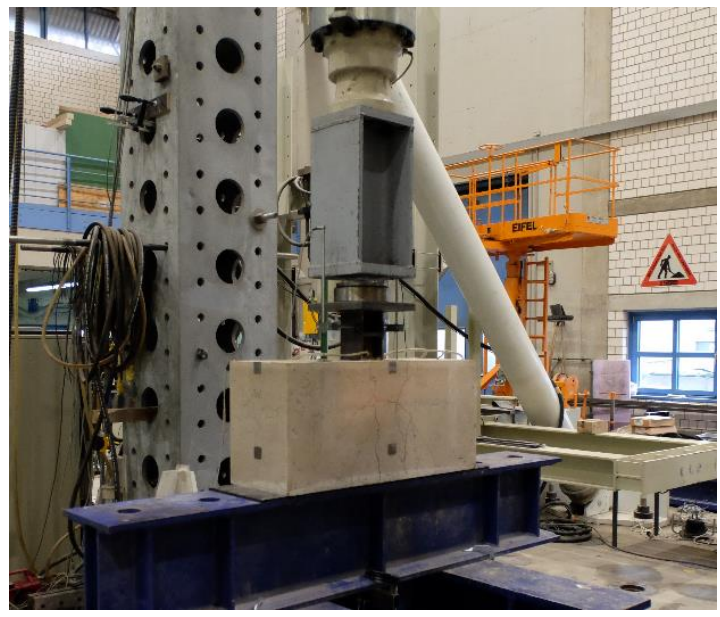

Fig. 8. Test arrangement at the TU-K.

\subsection{Measurement equipment}

The measurement equipment included a set of 13 Linear Variable Displacement Transducers (LVDT) and a variable set (from 2 to 11) of Strain Gauges (DMS), depending on the specimen type. The DMS's were glued to the steel profile's web and to the reinforcement cage. Records from the DMS's have been used to evaluate the distribution of forces within the specimen and to measure a level of force taken by the shear connector. In Table 4, a summary of the used LVDTs is given. The arrangement of the used LVDTs is presented in Fig. 9. To measure the relative slip between the steel 
profile and the concrete block, two LVDTs were fixed to bars welded to the embedded steel profile, above the concrete block, see Fig. 7 and Fig. 8. With the displacement of the steel profile, the relative slip has been measured.

Table 4. Measurement equipment list - LVDT.

\begin{tabular}{ccc}
\hline No. & LVDT No. & Position \\
\hline 1. & DT-1 & Steel profile bottom \\
2. & DT-2 & Steel, relative slip, left \\
3. & DT-3 & Steel, relative slip, right \\
4. & DT-4 & West wall, top \\
5. & DT-5 & West wall, bottom \\
6. & DT-6 & East wall, top \\
7. & DT-7 & East wall, bottom \\
8. & DT-8 & South wall, top \\
9. & DT-9 & South wall, bottom \\
10. & DT-10 & North wall, top \\
11. & DT-11 & North wall, bottom \\
12. & DT-12 & Frame, base deflection \\
13. & DT-13 & Frame, base deflection \\
\hline
\end{tabular}
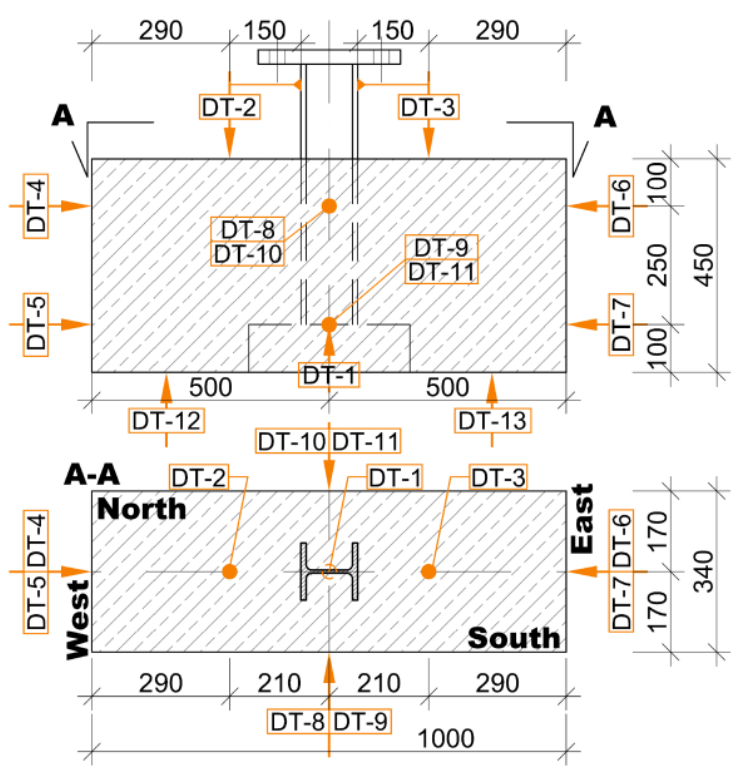

Fig. 9. LVDT arrangement.

\subsection{Test results}

For each type of the specimen, the load-slip responses indicated a specific and characteristic shear connection behaviour, see Fig. 10-13. On the presented diagrams, the indicated values of the relative slip have been evaluated as an average of two recorded signals measuring the relative slip independently at the same time LVDT DT-2 and LVDT DT-3 (see Table 4 and Fig. 9).

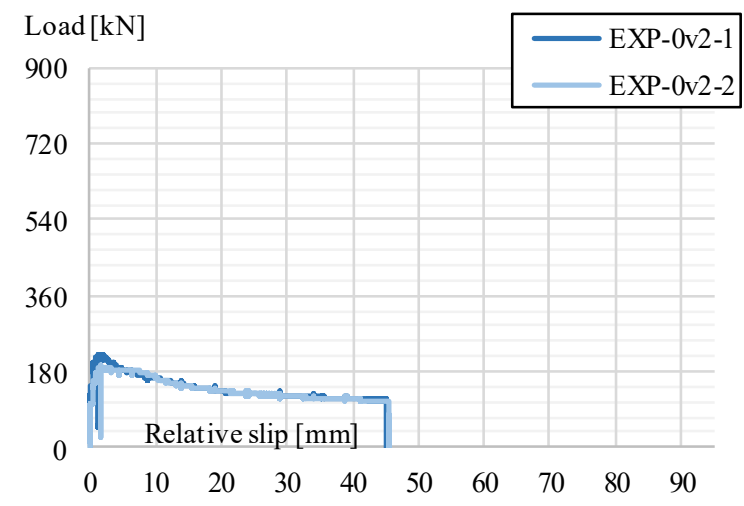

Fig. 10. Test results, load-slip curve - 0v2 type.

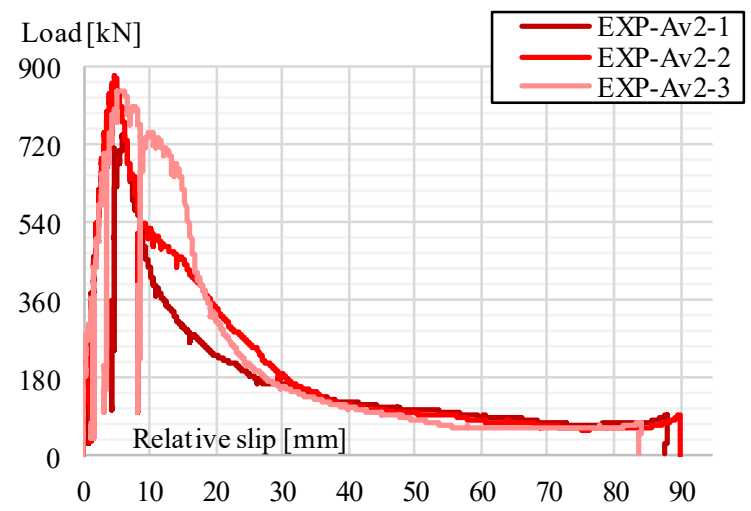

Fig. 11. Test results, load-slip curve - Av2 type.

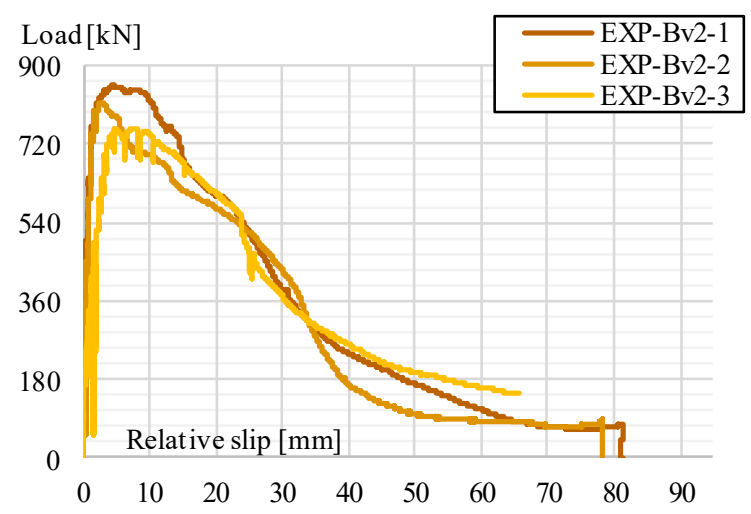

Fig. 12. Test results, load-slip curve - Bv2 type.

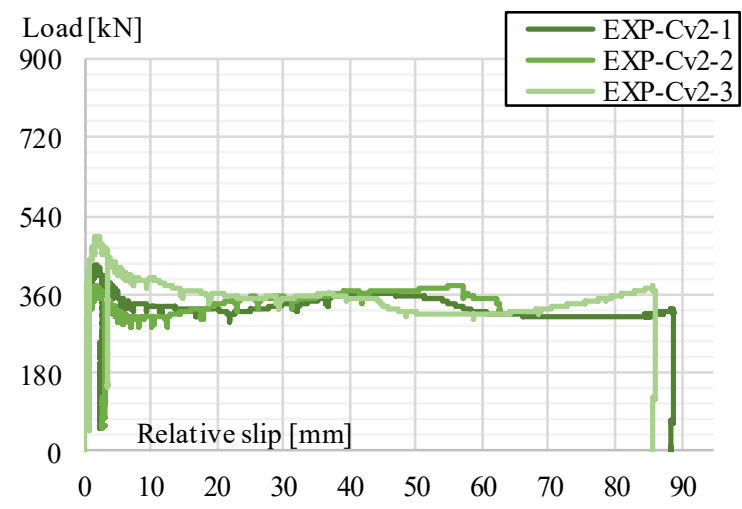

Fig. 13. Test results, load-slip curve-Cv2 type. 
In the specimen 0v2-3, a geometrical imperfection has been noticed - non-verticality of the steel profile, which significantly influenced the behaviour. In the result, this specimen has been omitted.

The experimentally obtained values are summarized in Table 5. The normal separation, measured as an expansion of the specimen walls, fits within tolerances defined in EN1994-1-1, Annex B, B.2.5(3) [8] (see Eq. (1)). The obtained normal separation varied between $0.01-1.00 \mathrm{~mm}$, where the max verification ratio reached $67 \%$.

$\delta_{n, u 80 \%} \leq 0,5 \cdot \delta_{l, u 80 \%}$

Where,

$\delta_{n, u 80 \%} \quad$ Normal separation at $80 \% \mathrm{~F}_{\mathrm{u}}[\mathrm{mm}]$

$\delta_{l, u 80 \%} \quad$ Relative slip at $80 \% \mathrm{~F}_{\mathrm{u}}[\mathrm{mm}]$

Table 5. POT results.

\begin{tabular}{|c|c|c|c|c|c|c|}
\hline $\begin{array}{c}\text { Specim } \\
\text { en }\end{array}$ & $\begin{array}{c}\mathbf{F}_{\mathbf{u}} \\
{[\mathrm{kN}]}\end{array}$ & $\begin{array}{c}\mathbf{F}_{\mathbf{6}} \\
{[\mathrm{kN}]}\end{array}$ & $\begin{array}{c}\boldsymbol{\delta}_{\mathbf{u}} \\
{[\mathrm{mm}]}\end{array}$ & $\begin{array}{c}\boldsymbol{\delta}_{1} \\
{[\mathrm{~mm}]}\end{array}$ & $\begin{array}{c}\boldsymbol{\delta}_{2} \\
{[\mathrm{~mm}]}\end{array}$ & $\begin{array}{c}\mathbf{K} \\
{[\mathrm{kN} /} \\
\mathrm{mm}]\end{array}$ \\
\hline-1 & 221 & 182 & 1.49 & 0.52 & 3.43 & 389 \\
\hline $\begin{array}{ll}\mathbf{v} & \\
\mathbf{2} & -2\end{array}$ & 194 & 182 & 1.64 & 0.93 & 6.95 & 287 \\
\hline Mean & 208 & 182 & 1.56 & 0.72 & 5.19 & 338 \\
\hline-1 & 746 & 740 & 4.06 & 2.97 & 6.89 & 390 \\
\hline-2 & 881 & 777 & 4.69 & 3.67 & 5.83 & 428 \\
\hline-3 & 847 & 844 & 5.64 & 4.35 & 8.44 & 545 \\
\hline Mean & 825 & 787 & 4.80 & 3.66 & 7.05 & 454 \\
\hline-1 & 854 & 843 & 4.51 & 1.39 & 11.78 & 968 \\
\hline-2 & 816 & 740 & 2.84 & 1.33 & 6.19 & 886 \\
\hline-3 & 757 & 741 & 8.00 & 3.21 & 14.66 & 520 \\
\hline Mean & 809 & 775 & 5.12 & 1.98 & 10.88 & 791 \\
\hline-1 & 429 & 344 & 1.87 & 1.08 & 3.55 & 545 \\
\hline-2 & 380 & 312 & 1.95 & 1.06 & 3.95 & 576 \\
\hline-3 & 496 & 410 & 1.90 & 1.08 & 3.93 & 740 \\
\hline Mean & 435 & 355 & 1.91 & 1.07 & 3.81 & 620 \\
\hline
\end{tabular}

$\mathrm{F}_{\mathrm{u}}$ - Peak load,

$\mathrm{K}$ - Shear connection stiffness at $\delta=0.5 \mathrm{~mm}$,

$\mathrm{F}_{6}-$ Load level at $6 \mathrm{~mm}$ of relative slip,

$\delta_{\mathrm{u}}$ - Relative slip at peak load,

$\delta_{1}$ - Relative slip at $90 \%$ of peak load, before failure,

$\delta_{2}$ - Relative slip at $90 \%$ of peak load, after failure,

\section{Failure pattern analysis}

In order to accurately investigate the failure pattern, the specimens were opened after the test execution. The specimens were cut with a concrete saw to separate the encasement. This allowed to trace the damage of the concrete around the shear connectors and to identify the critical shear planes.

The specimens 0v2 and Cv2 were characterised by a bond-type failure and the critical shear plane was developed at the steelconcrete interface (see Fig. 14). The existence of longitudinally welded reinforcement bar (Cv2) resulted in a failure similar to the rebar pull-out failure (splitting vertical crack observed on the specimen walls). This mechanism has been also observed by Bigaj [11] and Lundgren [12] for rebars.

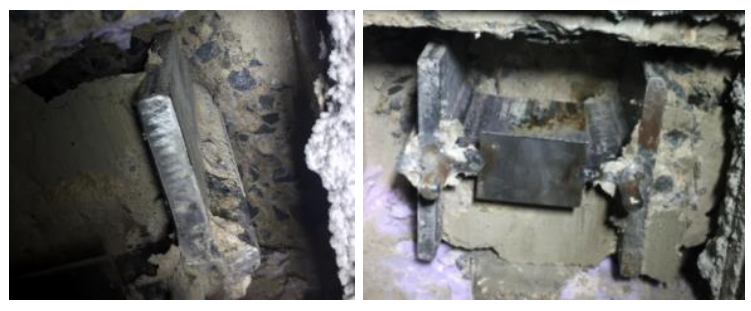

Fig. 14. Bottom view, slide of steel profile, Cv2.

In Fig. 15, a scheme of the shear plane localization is given for the Av2 type specimen. The shear plane was composed out of 3 planes, where the first plane was parallel to the steel profile's surface. Directly under the shear connector, a high confinement of the concrete took place and a backward shear plane at the boundary line between the different state concrete parts developed under the angle of about $15^{\circ}$ (see Fig. 16). For the Bv2 variant, a critical shear plane under $16^{\circ}$ can be identified (see Fig. 17). In addition, diagonal internal cracks under $45^{\circ}$ were noticed behind the shear plane - a rebar-type pull-out failure behaviour.

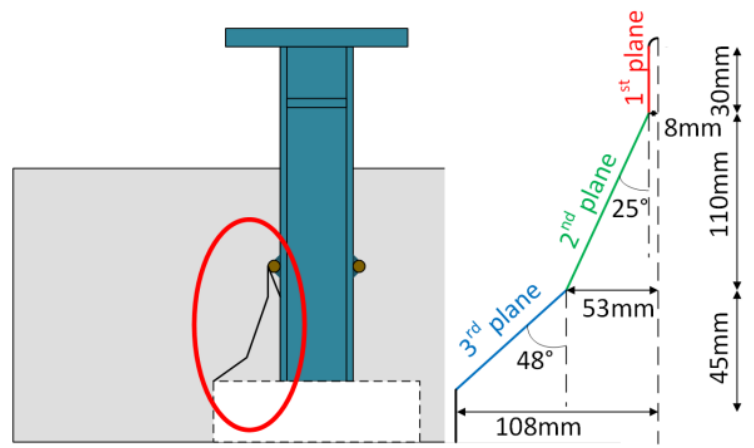

Fig. 15. Critical shear plane and scheme of Av2.

Failure of the specimens Av2 and Bv2 was accompanied by the development of diagonal cracks at the specimens' walls. The identified major cracks had an inclination of approx. $45^{\circ}$ and $16^{\circ}-27^{\circ}$ angle for Av2 and Bv2 specimens, respectively (see Fig. 16 and Fig. 17). 


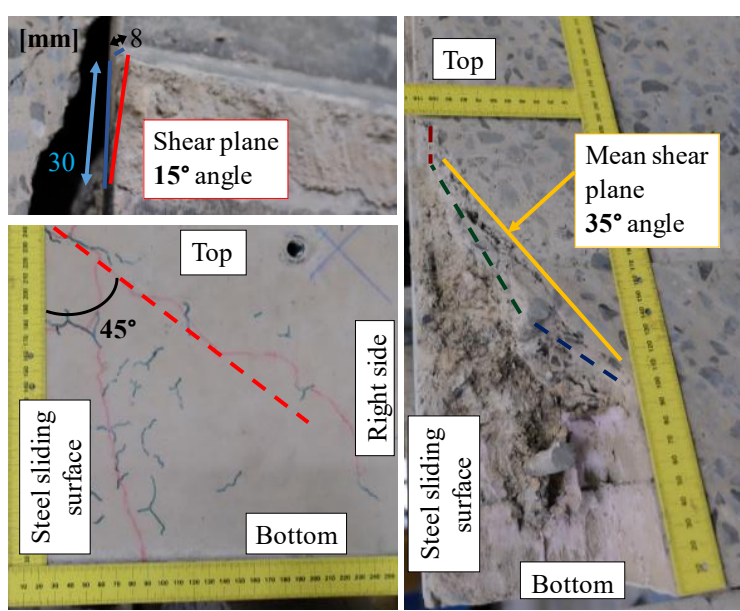

Fig. 16. Failure pattern - Av2.

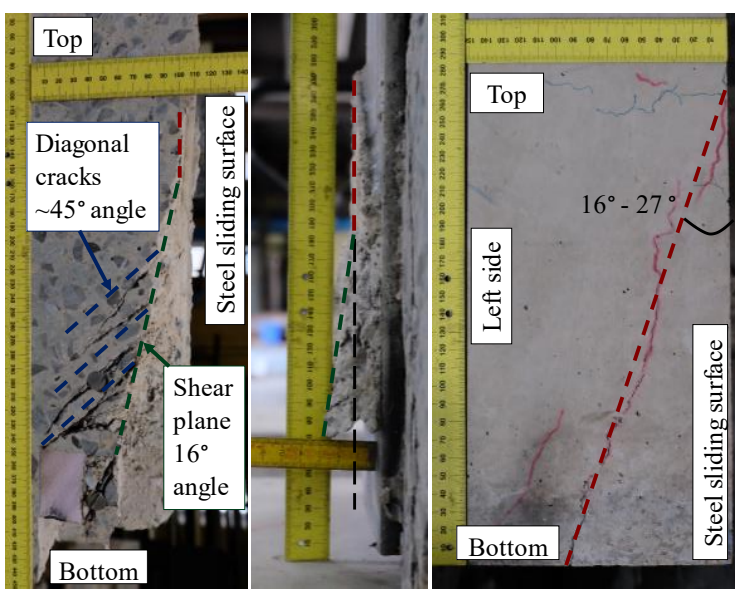

Fig. 17. Failure pattern - Bv2.

\section{Numerical simulations}

The performed investigation is supported by numerical simulations with the usage of Abaqus FE code [13]. The created models are reflecting the experimental POT. A model analysing sequence $(0 \mathrm{v} 2 \rightarrow \mathrm{Cv} 2 \rightarrow \mathrm{Av} 2 \rightarrow \mathrm{Bv} 2)$ is allowing a good understanding of the occurring phenomena. The applied material laws for the steel part and rebars are incorporating an elasticplastic linear material law with strain hardening and damage. For the concrete part, the Concrete Damage Plasticity (CDP) model based on the fib Model Code 2010 [15] was used. The concrete part and the steel profile part were discretized with hexahedral C3D8R finite elements, where the rebar cage was modelled with B32 elements.

The steel-concrete bond was modelled with the usage of cohesive interaction properties. The method proposed by Chrzanowski et al. [13] was adapted and calibrated for the bigger scale POT, according to the experimental results. The same method has been used to simulate the rebar- concrete bond. In the result, a complex interaction model has been obtained which is incorporating (i) a tabular damage definition of the cohesion behaviour, (ii) the Coulomb friction and (iii) the mechanical dowel action. The obtained numerical load-slip behaviour of the model without mechanical connectors (0v2) showed very good convergence to the experimental curves (see Fig. 18).

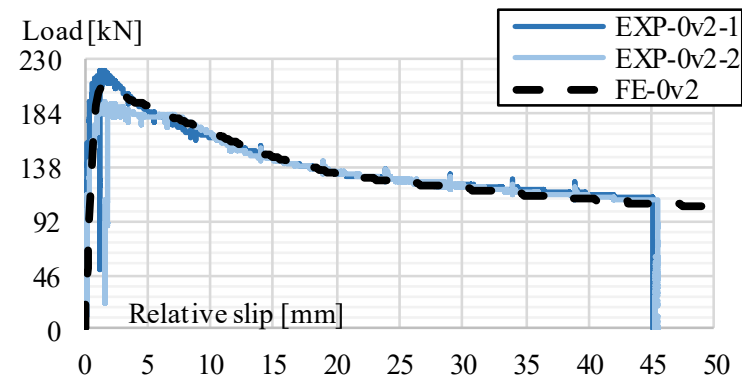

Fig. 18. FE load-slip curve-0v2 type.

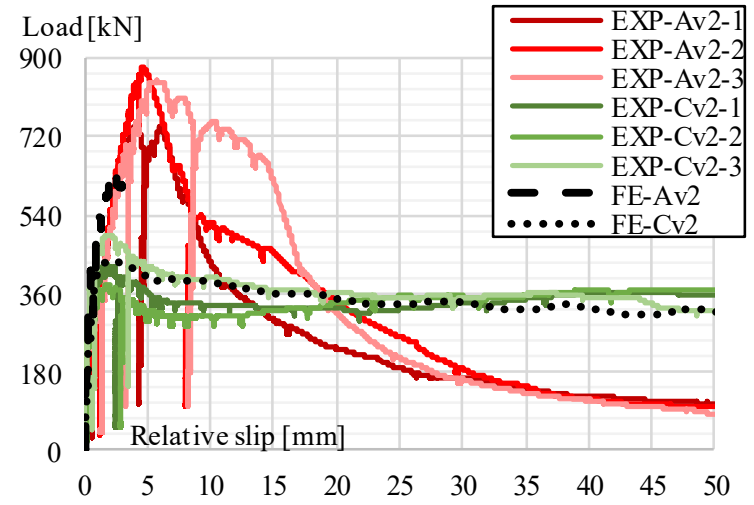

Fig. 19. FE load-slip curve - Av2 and Cv2 type.

The given load-slip responses of Cv2 and Av2 type specimens (see Fig. 19) show a good convergence with the measured behaviour. The Av2 model is still under calibration in order to obtain the remaining part of the load-slip response. The Bv2 type model is including a very complex shape of the connector and thus, a very complex interaction at the steel-concrete interface (see Fig. 20). Due to that, the current FE model requires a further investigation.

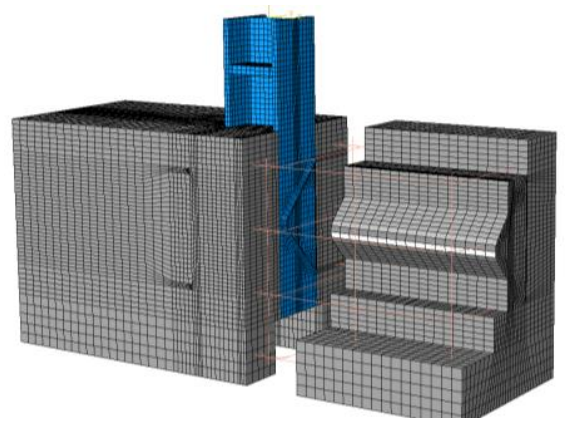

Fig. 20. FE model of Bv2 type specimen. 


\section{Summary and conclusions}

Three different types of shear connectors and one reference type without connector were presented with their respective load-slip behaviour. The investigations show, that the observed load-bearing behaviour is sensitive to and are strongly relating on:

- the combination of the used geometrical layout and the boundary conditions,

- the weld and size of the connector itself,

- the material properties of the used parts

- the concrete confinement in form of stirrups.

Connector type $\mathrm{Cv} 2$ indicated the poorest load-bearing performance and the biggest amount of material was used for its fabrication. The connector Av2 showed a similar loadbearing capacity like Bv2 type, whereas Bv2 had a much higher ductility and stiffness level. Based on the gathered data and on compromise between the load-bearing capacity and the ductility, it can be concluded that the connector $\mathrm{Bv} 2$ is performing the best and it could be taken into account as an optimised type of shear connector dedicated to composite columns.

To fully understand the behaviour of the proposed new type of shear connector and to develop an accurate analytical model, further experimental tests, as well as numerical simulations, are highly demanded. Mentioned analytical model is under the development within the scope of the presented research project. The given results shall not be considered without the combination of the given parameters.

\section{Acknowledgments}

The MultiCoSteel research project is running in a collaboration with the industrial partner ArcelorMittal. It is funded by the National Research Fund, Luxembourg, FNR AFR-PPP PhD Grant (Call 2016-1), Proj. Ref. 11283614. Numerical experiments presented in this paper were carried out using the HPC facilities of the University of Luxembourg - http://hpc.uni.lu.

\section{References}

[1] Nethercot DA. Composite Construction. Spon Press, 2003. ISBN-0-415-24662-8.

[2] Lungershausen H. Zur Schubtragfähigkeit von Kopfbolzendübeln. Mitteilung Nr. 88-7, Tech. rep., Institut für Konstruktiven Ingenieurbau, Ruhr-Universität Bochum, 1988.
[3] Lam D, El-Lobody E. Behaviour of Headed Stud Shear Connectors in Composite Beam. Journal of Structural Engineering 131 (96-107), 01.2005.

[4] Degée H, Plumier A, Bogdan T, Popa N, Cajot LG, De Bel JM., Mengeot P, Hjiaj M., Nguyen QH., Somja H, Elghazouli A, Bompa D. Smart Composite Components - Concrete Structures Reinforced by Steel Profiles, SmartCoCo. European Commission, Research Programme of the Research Funds for Coal and Steel, TGS 8, Grant Agreement RFSR-CT-2012-00031, 2016.

[5] Vianna JC, Andrade SAL, Vellasco PCGS, Costa-Neves LF. Experimental study of perfobond shear connectors in composite construction. Journal of Constructional Steel Research 81 (62-75), 2013.

[6] ANSI/AISC 360-16, American Institute of Steel Construction. Specification for Structural Steel Buildings. An American National Standard, July 2016.

[7] ACI 318-14, American Concrete Institute. Building Code Requirements for Structural Concrete and Commentary. ACI Standard, September 2014.

[8] EN1994-1-1, European committee for standardization. Eurocode 4: Design of composite steel and concrete structures. Part 1-1: General rules and rules for buildings. European standard, December 2004.

[9] JSCE, Japan Society of Civil Engineers. Standard Specifications for Steel and Composite Structures. JSCE 2009, December 2009.

[10] JGJ 138-2016, Chinese code. Code for design of composite structures, December 2016.

[11]Bigaj AJ. Structural Dependence of Rotation Capacity of Plastic Hinges in RC Beams and Slabs. PhD Thesis, Technische Universiteit Delft, Delft, Netherland, 27.09.1999.

[12] Lundgren K. Three-Dimensional Modelling of Bond in Reinforced Concrete. Theoretical Model, Experiments and Applications. $\mathrm{PhD}$ Thesis, Chalmers University of Technology, Göteborg, Sweden, 1999. ISBN-91-7197-853-4.

[13] Chrzanowski M, Odenbreit C, Obiala R, Bogdan T. Shear stresses analysis at the steel-concrete interface with the usage of bond eliminating products. XI Congresso CMM, Coimbra, Portugal, proceedings (1027-1036), 11.2017. ISBN-978-989-99226-6-2.

[14] SIMULIA User Assistance 2017. Abaqus, (C) Dassault Systèmes Simulia Corp. All rights reserved, Providence, RI, USA.

[15] fib ModelCode 2010, International Federation for Structural Concrete (fib). Ernst\&Sohn, 2013. 